\title{
Economic developments in a globalized world
}

\author{
Elias Soukiazis
}

Published online: 19 April 2013

(C) Springer-Verlag Berlin Heidelberg 2013

This special issue includes a number of selected papers that analyze different topics with the aim to explain the interrelations between economies in a highly integrated and globalized world. Although the focus is given on the European or OECD space, studies are also referred to developing countries turning this volume more interesting in the context of the global worldwide integration. A number of different issues are raised analyzing important economic areas in a systematic way not only from the theoretical point of view but mostly providing empirical evidence that turn the theoretical arguments more convincing.

This volume, in particular, accommodates three types of studies. The first part includes two papers on labour unit cost and business cycle synchronization, respectively, the former focusing on the European Union members and the later considering a broader range of 111 countries. Business cycle synchronization is of extreme importance as a consequence of higher integration which is also expected to bring substantial adjustments in labour markets in the absence of an independent monetary policy and living in a fixed exchange rate regime. The second part of the special issue deals with financial markets in the perspective of bank efficiency and concentration of banking activities. The deepening of financial market integration is supposed to induce more competition and consequently higher efficiency in the perspective of cost reduction strategy. The stock exchange market behavior among the most important European Union countries is also a subject of analysis in the context of the volatility transmission and higher integration. In a system of free capital mobility and higher capital integration the transmission mechanism is expected to be higher leading to a more tight interdependence of the financial markets. The third part of this special issue hosts studies with special reference to developing and developed countries enhancing therefore a global perspective of economic development. Exchange rate policies and the pass-through hypothesis are still of an extreme importance for the developing countries from the point of view of economic policy and further economic development. Issues of income inequality and how do they affect economic growth are of extreme importance when designing redistributive policy

\footnotetext{
E. Soukiazis $(\square)$

Faculdade de Economia, Universidade de Coimbra, Gab. 519, Av. Dias da Silva 165, 3030-512

Coimbra, Portugal

e-mail: elias@fe.uc.pt
} 
interventions. The causality between oil and gold prices and pass-through effects on the U.S. prices and the dollar exchange rate are interesting topics to consider from the perspective of global integration.

This special volume starts with the study by Sofia Gouveia and Leonida Correia who analyze the synchronization of labour cost cycles in the euro area in the context of the optimum currency area theory. The methodology used is based on the correlation coefficients between the labour cost cycle of each country and that of the euro area aggregate as well as on the other measures referred to the mean and standard deviation. Analyzing the data they show that nominal wages, labour productivity and nominal unit labour costs are heterogeneous across the euro area countries and the biggest differences are between the Northern and Central European countries on the one hand, and the Southern countries and the new EMU economies on the other. The nominal unit labour cost analysis shows an increase in all euro area countries contributing to differences in nominal unit labour cost performance across countries. On the other hand, the trade balance dynamics reveal that there has been deterioration in competitiveness in the Southern European countries and that trade imbalances widened considerably between the euro area members after the introduction of the euro. The comparative analysis by sub-periods shows that almost all the euro area countries have tightened the synchronization of labour costs with the euro area cycle in the period of circulation of the euro comparing with the previous one. Dispersion measures of cyclicality show cross-country heterogeneity and that the euro period has produced higher cyclical dispersion than the previous period. Furthermore, during the crisis period, almost all countries displayed intensification in the volatility of their cycle. The general conclusion is that some signs of labour cost convergence emerge in the euro area and that after the circulation of the euro, a reduction in nominal unit labour costs differences and an increase on the degree of synchronization has occurred, which are strengthened in the years of the economic and financial crisis. However, the labour markets in the euro area are yet very heterogeneous, implying that some euro area members remain vulnerable to asymmetrical shocks.

The paper by Pedro André Cerqueira uses a non-parametric estimation approach to analyze the behavior of the synchronization for a sample of 111 countries over the period 1960-2007. The author builds his own period-by-period synchronization index that is able to distinguish between negative correlations due to episodes in single years, asynchronous behavior in turbulent times and synchronous behavior over stable periods. The empirical results of his study show that until the 1990 the synchronization level had fluctuated between troughs and peaks at more or less the same levels. In particular the period-by-period synchronization index shows that worldwide business cycle synchronization had two troughs, the biggest in the midseventies and a smaller one around 1990. However, after 1990 the synchronization level has experienced a substantial increase not only at a global level but also within geographic and income groups reaching the maximum values ever. Therefore, strong evidence is found to support the hypothesis that after the nineties the globalization process increased worldwide business cycle synchronization.

Financial market developments are important for understanding global and regional integration. The paper by Candida Ferreira studies empirically the controversial relationship between bank market concentration and bank efficiency by employing a panel Granger causality approach on a sample of 27 European countries for the period 
1996-2008. Using specific measures of bank market concentrations she finds that there is a general increase of the EU bank market concentration over the considered period with the exception of lower levels of concentration regarding the largest EU countries (France, Germany, Spain, the United Kingdom and Italy). By using a DEA non-parametric estimation approach to measure the bank's cost efficiency she finds a declining trend of this cost efficiency more pronounced in the late years considered. She testes statistically the panel Granger causality between the EU bank market concentration and the cost efficiency by using robust estimation techniques and she finds evidence allowing to conclude that the causality runs from concentration to efficiency and that this relationship is clearly negative. This result collaborates the idea that the banks acting in more concentrated markets will contribute to inefficiency as a result of their lesser efforts to acquire more outputs with less costs. The general conclusion is that smaller banks are more efficient and that even when larger banks have higher performance, this advantage decreases in more concentrated markets. The evidence is clear for the 27 European countries that more cost-efficient banks operate in less concentrated markets.

The paper by José Soares da Fonseca is an empirical analysis evaluating the linkages between the five biggest Euro area stock markets: France, Germany, Holland, Italy and Spain. The author tests an EMU market model with time-varying beta coefficients and these are used to calculate Treynor ratios which provide information on the comparative performance of those markets. The empirical analysis proceeds with the estimation of VAR models which provide evidence of a limited innovation and volatility transmission between the considered stock markets over the period 2001-2011. A comparative performance analysis distinguishes two groups, the first consisting from the French and the German and the second includes the Dutch, Italian and Spanish stock markets, with very close average ratios, but with a higher level than those of the first group. The general conclusion is that the considered stock markets have not been perfectly integrated during the first decade of the European Monetary Union.

Moving away from financial markets in the euro area, the paper by Mouyad Al Samara, Cindy Moons and Jan Van Hove considers a special case of a developing country referred to Syria. The authors study the exchange rate pass-through hypothesis in the Syrian economy over the period 1990-2009. Due to a multiple exchange rate regime and prices regulations combined with an unstable monetary policy environment the exchange rate pass-through effect on inflation is likely to be more substantial in this country. The authors construct a cost of imports indicator and relate it to the consumer price index to test the exchange rate pass-through hypothesis. The empirical analysis based on the Autoregressive Distributed Lag (ARDL) approach validates the conventional finding that the exchange rate pass-through into consumer prices is high in developing countries. The evidence point to a high and fast exchange rate pass-through effect concluding therefore that the Syrian macroeconomic performance is highly dependent on the international price fluctuations as well as on the country's currency depreciation. The high and fast exchange rate pass-through effect implies that currency depreciation will cause a strong inflationary pressure on the Syrian economy. As a consequence, it will be hard to implement a price stability policy and stable real economic growth as long as exchange rate fluctuations occur. 
Marta Simões, João Andrade and Adelaide Duarte investigate the relationship between earnings inequality (measured by the Gini index) and economic growth using panel data for 30 Portuguese NUTS3 regions over the period 1995-2007. The authors employ dynamic panel cointegration techniques to perform growth regressions. Overall their results support the idea of a significant relationship between the earnings distribution and per capita output at a regional level, but the sign of the relationship depends on the size of inequality. Although there is evidence that higher earnings inequality affects negatively per capita output especially at a lower levels of earnings, the relation is adverse at the top of the earnings distribution. Besides earnings inequality, human capital is also an important covariate in explaining regional output in Portugal, but structural funds didn't help the regions to improve their output. The excessive specialization in non-tradable goods made possible by the European funds should be the explanation of this disappointing result.

Finally, Joscha Beckmann and Robert Czudaj provide a study aiming to disentangle the underlying causalities between the oil and gold price dynamics and their relation to U.S. prices and the dollar exchange rate. The authors, using monthly data for the nominal effective dollar exchange rate, oil, gold and U.S. prices from 1976:01 to 2011:11, analyze the long-run and short-run dynamics and the long-run impact in terms of shocks, applying a cointegrated VAR model. The main conclusions derived from this empirical study shows that although gold and oil are both important commodities, their economic impact measured by shocks on their prices differs significantly. In the long-run, both quantities seem to be positively related and shocks to the gold price drive the system. On the other hand, the gold-oil spread is positively related to the U.S. consumer prices, implying a stronger relationship of consumer prices to the gold-oil prices. More specifically, an increase in the price of gold depreciates the dollar, and the price of oil and the effective dollar exchange rate are positively related. Evidence also shows that the causality is more likely to run from gold prices to oil prices (gold prices translate positively into oil prices) but the relationship between gold and oil has weakened over time. Considering instabilities in the form of structural breaks and time-varying short dynamics should be an extension to this study.

All the above selected papers make a significant contribution in the economic literature by discussing, providing empirical evidence and suggesting policies on different areas which are of a great concern in economic analysis especially in a new globalized world and high market integration. Issues on labour cost and business cycle synchronization; issues on financial markets considering bank efficiency and concentration of banking activities; the stock exchange market behavior in the light of the volatility transmission and higher integration; exchange rate policies and the passthrough hypothesis, income inequality and its importance on regional growth, and finally the dynamics involved between oil and gold prices and their impacts on the dollar price and inflation in the US are all important subjects considered in this volume. The discussion of all these topics is also very pertinent in the present days where the financial crisis dominates the political and economic debate, trying to find solutions to overcome the consequences of the economic decline. We hope that this special issue contributes significantly to this debate.

We are very grateful to the participants in the 14th annual INFER (International Network for Economic Research) conference held at the Faculty of Economics of the 
University of Coimbra, Portugal from 10 to 12 of May, 2012 where all these papers were presented. The aim of the conference was to bring researchers from different areas to present their work in a friendly environment and to discuss the analyzed issues, receiving constructive comments and suggestions. A vast number of different topics enhancing almost all the main economic areas were analyzed motivating an interesting and constructive discussion useful for designing new economic policies and developing further research. 